\title{
The Professional Development of Adult Educators: The Case of the Lifelong Learning Centres (L.L.C) in the Prefecture of Evros, Greece
}

\author{
Kyriaki Anthopoulou \\ English Language Teacher \\ Alexandroupolis, Greece \\ Efthymios Valkanos \\ Associate Professor, University of Macedonia \\ Thessaloniki, Greece \\ Iosif Fragkoulis \\ Professor, Hellenic Open University \\ Patras, Greece
}

\begin{abstract}
The purpose of the present study was to record the opinions of the Greek adult educators who were occupied in the Lifelong Learning Centres in the Prefecture of Evros during the academic year of 20162017, in relation to the concept of the professional development. The partial aims of this specific research were: the recording and comparison of their individual aspects regarding the skills, the training, the professional development as well as the certification of qualifications that modern adult educators should obtain. In order for the research to be realised and for the interpretation of the data the qualitative method was selected. This became feasible by individual interviewing on ten adult educators, who cooperated with the Lifelong Learning Centres existing in the Municipality of Alexandroupolis and the Municipality of Orestiada. After monitoring the participants' viewpoint, the collected data showed that there was certain converge relating the derived results around the skills that characterize an adult educator. The general opinion in the total of the educators was estimated encouraging regarding their professional development while simultaneously the latter proved to possess great potential progress. Although the majority of the adult educators took part in continuous educational programs, they found them someway insufficient. In conclusion, it was obvious that the overwhelming majority of the participants did not certify their qualifications.
\end{abstract}

Keywords: Adult educators; Skills; Professional development; Certification of Qualifications; Lifelong Learning Centres. 


\section{Introduction}

Life long or continuing learning during adulthood is considered a global phenomenon, sourcing from the rapid changes occurring in the technological, scientific and sociopolitical contexts (Tsopozidou, 2014). An adult educator is one of the fundamental elements of the non formal educational system. Therefore, a significant voluminous Greek and international literacy is available concerning this complex term. Many academics such as Jarvis, Rogers, Courau etc, attempted to conceptualize the educator's professional identity and to elucidate the required qualifications.

Generally, any individual who desires to impart any kind of knowledge could be characterized as an adult educator (Jarvis, 2004). Specifying on the Greek terms, a person who teaches adults may be a university Professor or a person who is occupied in the non formal educative structures. Accordingly, adult educator may also be a Primary or Secondary teacher who trains his colleagues taking part in literacy classes or even a business executive when large corporations organise training programmes for their employees. Rogers (1999) stated that adult educators are considered not only the individuals who teach but also those who plan educative programmes and more specifically, the advisors or the overseers. In addition, the Greek legislation declared during 2012 that adult educators are the persons who maintain the typical and the substantive qualifications rating the Cert for Educators of Adults in the highest priority (Greek National Organisation for the Certification of Qualifications \& Vocational Guidance [EOPPEP], 2012). Considering the relevant literacy there is a classification among the teachers concerning their working status (Jarvis, 2004). The first category refers to those who hold a full time job, working mainly on the public sector, being the minority of the whole (Kedraka, 2009) and consecutively to those who have teaching assignments per hour. The second category is consisted of the majority of the educators and it is limited to the teaching of their specialty basically as a supplementary type of occupation.

\section{Gaining Qualifications}

Any educator wishing to be effective should possess numerous skills differentiating him radically from the traditional teacher's type. It is commonly recognised that assets associated with an adult instructor are synthetically complex hence there is a combination of different scientific fields. Except from the pedagogical certification, skills stemming from psychology, technology and sociology are crucial to be attained (Tsakirides, 2016).

This skilful person obtains two categories of qualifications. The typical, that refer to the gained degrees, diplomas or certificates and the substantial that refer to the shape of the behaviour and other characteristics that the educator has acquired from his working experience in various contexts. The gained qualifications appear three dimensional: Knowledge, skills, behaviours. Furthermore, an educator should possess: teaching abilities, good communication skills, patience, adaptability, flexibility, empathy, critical thinking and role adoption (Mockler \& Noble, 1981). In Greece, the individual who desires to gain professional education and to follow professional career on the field of adult education could attend university studies, undergraduate or 
post graduate, seminars or short term training programmes. It should be mentioned that the European Centre for the development of vocational training [CEDEFOP] (2009) gave credits to the updated threefold of pedagogical training, professional skills and to the motive of triggering the desire to work as adult educator.

As it occurs in many developed countries, in the Greek system, an adult educator is not a completely shaped profession, the qualifications are penurious and inappropriate, but simultaneously the existed training programmes are essential as they promote new knowledge, information, progress and professional development.

\section{Professional development of adult educators}

The term professional development is pivotal for this study. It was firstly referred in the decade of 1970s. A great number of studies on the professional progress played a significant role to the lifelong learning. Hence, it is considered as a lifelong lasting process while it strongly constitutes a personal hypothesis. More specifically, as a person matures it measures his personal perception, his working conditions and his personal abilities and inclinations (Greenhaus, 1987). A part of Greek researches proved that the professional development starts from an early age creating working stereotypes.

Professional developmental state is not a static and linear condition but it appears as a deep time consuming self interaction stemming from financial, psychological, and sociological parameters. Thus, it is true that progresses made to the profession mean additionally personal and sociological development or as Levinson (2002) strongly supports when age is combined with experience leads to progress.

In a parallel concept, the adult educators' professional evolvement arose during 1980s, in order to upgrade the lesson quality and to meliorate the role of the educator. An intense need in development is expressed due the factor that society changes dramatically, the technology emerges rapidly, new teaching methods are continuously added and therefore the acquired skills are not enough. This notion keeps the professional status intact from many out generated factors as the aforementioned. The developmental process includes all kinds of knowledge, except for the typical, that an educator acquires from his systematic work on the adult education field. Those elements are derived mainly from his participation in the non formal education. Approaching holistically the professional development of an adult educator incorporating it in the daily life is a modern tendency. Morphologically, the term is appeared to specific forms as Training, Post graduate studies on Adult Education, Apprenticeship, Seminars, Conferences, Lectures, Assessment, and Libraries aiming in self enriching, cooperation and aspect exchange. Obtaining certain characteristics promotes cooperation and participation while it is ongoing, it has certain duration, it promotes self evaluation, critical thinking, reflective skills, it is teacher driven, it insists on applying the theory to practice and it is part of changing processes. 
Among the applied teaching models that support the professional development in adult education the best known are the critical, the interpretative and the stochastic one because they focus on instructors' personal, educational and organizational tangible needs being recognized as professional developing modes. Training and certification are the two principal factors which promote professional development (Blackman, 1989).

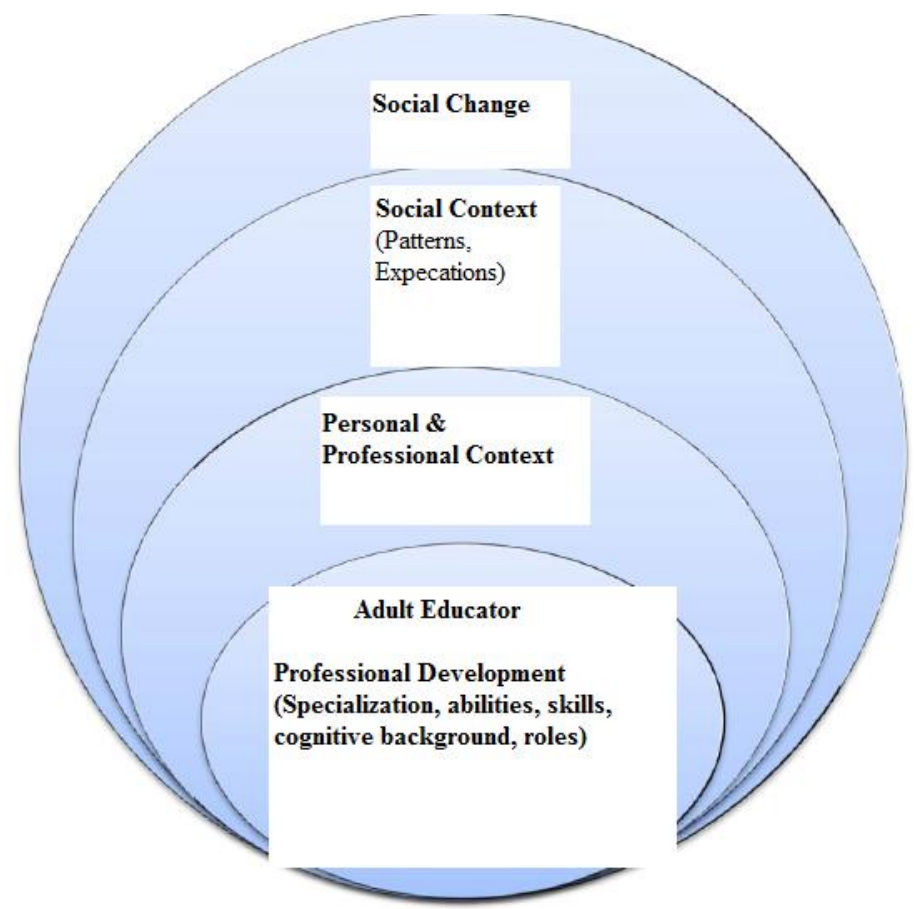

Figure 1. Adult educators' prerequisites for professional development according to Jogi \& Gross (2009).

\section{Certification of Qualifications and the Greek National Organisation for the Certification of Qualifications \& Vocational Guidance (E.O.P.P.E.P.)} The certification of the qualifications that an adult educator obtains has derived from the necessity and simultaneously from the absence to recognize officially the knowledge, the skills and the behaviors that the individuals have achieved in and out of the educational system in a proper function. The existence of an established national certification system fosters the financial field (Tsopozidou, 2014). The employment market widens and is more competitive being framed by highly motivated employees. In Greece, the legislated criteria appeared after the 1990s, when adult education started to gain ground. During the year 1996 the National Centre for the Accreditation of Lifelong Learning Providers (EKEPIS) was founded under law and the first adult educators' registry became reality but it was considered mal organized and ineffective.

Progressively, the Greek National Organisation for the Certification of Qualifications \& Vocational Guidance - EOPPEP was founded in 2012 under the law and the Presidential Decree (EOPPEP, 2012) for the general adult education. EOPPEP is a Statutory Body supervised by the Minister of Education \& Religious Affairs, Culture \& Sports. The first regulated and proven qualifications 
of adult educators became a milestone for the professional career because its mission is to update and upgrade the occupational skills and to link the market with the personal needs providing at the same time recognition and reliability. In order for a person to get the certificate, the candidate should form his personal portfolio and according to the norms to take part in oral and written examinations. Today the individuals who gained the certification were listed around 32.000 (EOPPEP, 2012) is organized and linked to the European standards and policies. Greece appeared to develop an established system later than other countries. Hence, it is not fully developed. Greek gross domestic product spent on adult education seems low and it is estimated between 1 to 3 per cent (Tsigarida, 2014).

\section{The case of the Greek Lifelong Learning Centers}

Lifelong Learning Centers belong to the non formal education. They were established under the Greek Law N.3879/2010 (Lifelong Learning Centres $[\mathrm{kdvm}], 2014)$. Their principal objective is to promote lifelong learning completely gratis to any citizen who has turned the age of 18 and wants to enrich his existing knowledge, to acquire new or basic skills or finally if he wishes to find or to hold a job.

More specifically, Lifelong Learning Centres are a decentralised form of Institutes because it is on the municipalities' responsibility to perform types of adult education under the supervision of the Greek Ministry of Education \& Religious Affairs. They are implemented by the National Strategic Reference Framework (ESPA) conferred by the European Union. They offer two dimensional classes. The first are the national range programmes which refer to a vast theme zone: economy, business, life quality, technology, civilization, arts, history, and foreign languages. The second refer to the local range programmes that are opted by each municipality according to the local market needs. For the proper function of these centers more than seven public bodies cooperate.

The target of the Lifelong Learning Centers is to: create positive learning attitude, flexibility, availability and connection to the market place, familiarize people with technology, create active citizens, support the free access to education, upgrade the society, support sex equality, promote educative quality and certification due to the fact that these centers were recently linked to EOPPEP.

It is a democratic strategy with social mission for any prefecture which wishes to organize and materialize programmes adaptable to the needs of the citizens. Each programme lasts for 25 hours and each group is consisted of 25 persons. Adult educators who teach in those centers work voluntarily but they get a working experience certificate.

As far as the Lifelong Learning centers of Evros prefecture are concerned, the latter founded centers in all municipalities and more specifically in Alexandroupolis, in Orestiada, in Didimoteichon, in Souflion and in Samothrace. Due to financial problems the centers which operate are limited to two, fact that 
is a confining factor for the present research. Organized adult programmes that are offered by the two municipalities are related to foreign languages, computer literacy and agriculture due to the provincial character of the prefecture. Table 1 and table 2 depict the people's need to participate in the classes.

Table 1. Completed Programmes in LLC of Alexandroupolis from 2012 to 2016.

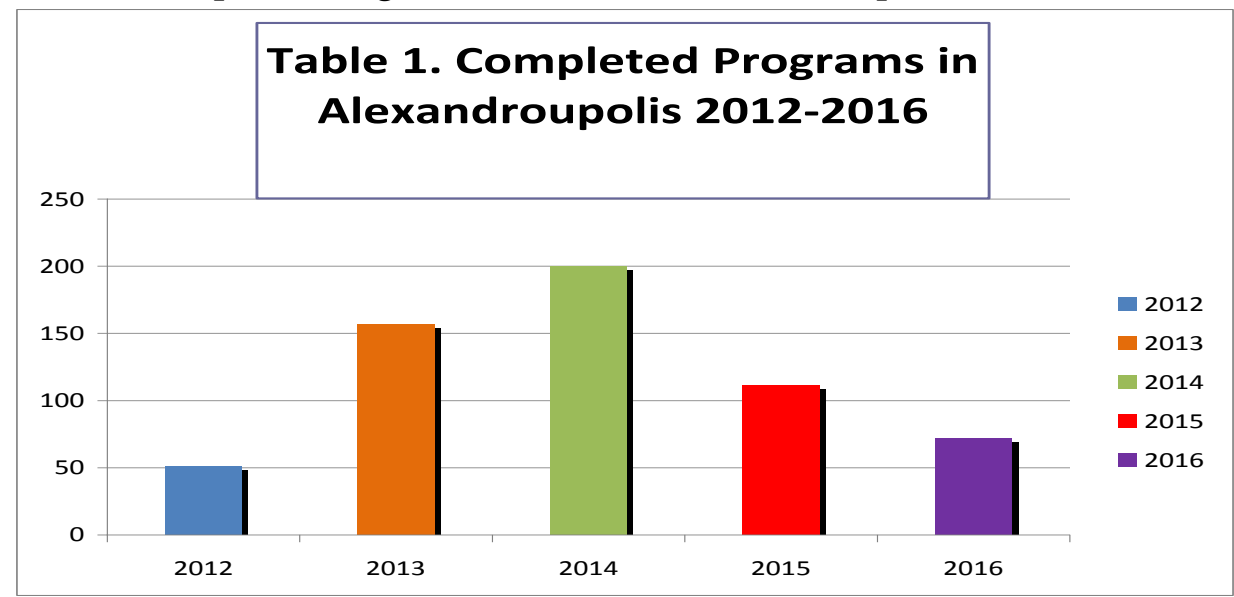

Table 2. Completed Programmes in the LLC of Orestiada from 2013 to 2016.

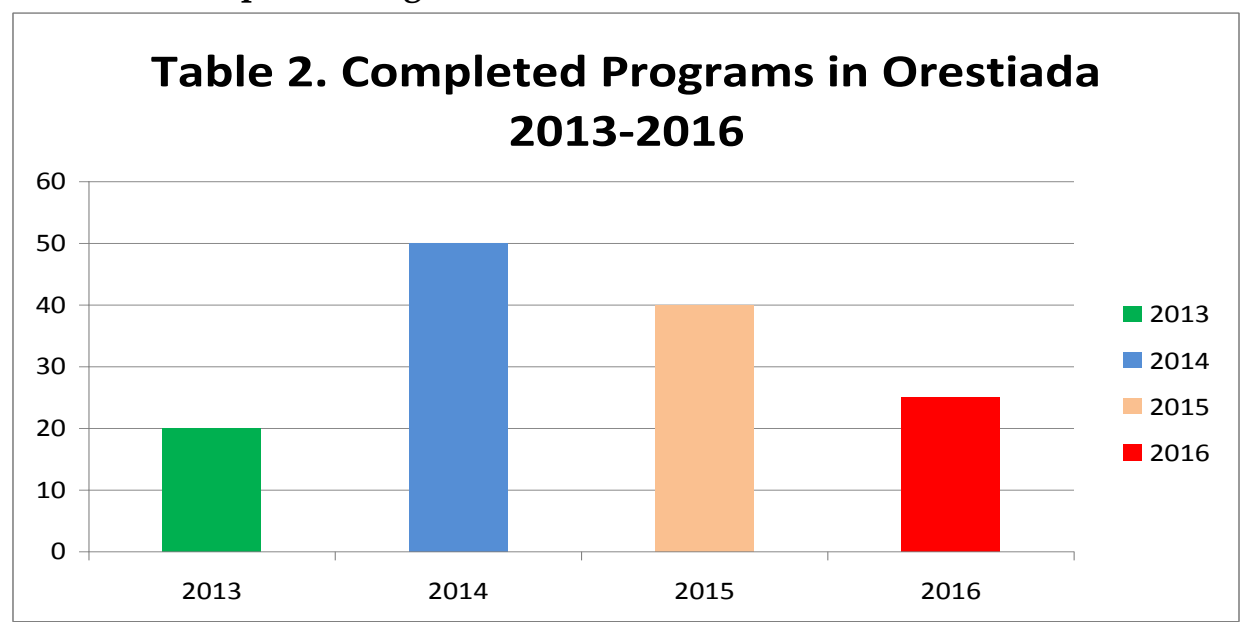

\section{Method}

The purpose of the approach was to monitor the educators' aspects on several questions relating to the fields of qualifications, continuous training and its essentiality, certification of qualifications and professional development. The data interpretation should respond to the four research questions formed for the feasibility of the present study. More specifically, the questions dealing with the topics were the following:

1. What are the basic skills that an adult trainer should possess?

2. Why do trainers are interested in continuing training and certification?

3. Do the programmes the educators' have attended respond to their needs?

4. Have the programmes affected on the educators' effectiveness?

The principal aim of this research was to highlight an educator's qualifications, to outline the professional development of the field and to scrutiny the extent 
that the educators are trained and certify their skills in terms of the acquired knowledge. In addition, the objectives of this work were to investigate whether the trainers consider necessary to participate in training and whether the programmes they participated in responded to their expectations.

A qualitative research was conducted for the sake of immediacy because such approaches are not considered to monitor parameters only on the surface of a theme but it copes with it in detail. Furthermore, clear and special points of view are expressed and the participants may easily share their personal experiences. Additionally, the critical thinking arises and it becomes feasible to tackle overgeneralizations. The reason behind the choice of the Lifelong Learning Centres of Evros Prefecture was to record if the professional development has an impact on the provincial areas.

\section{Time and place}

The research initialised after official and signed allowances were provided from each municipality. The interviews took place in the offices of the Lifelong Learning Centres in order to facilitate the educators' access. The research was conducted on the $23 \mathrm{~d}$ and the 24th of March 2017 in Alexandroupolis while the rest of the interviews were taken on the $28^{\text {th }}$ and the $29^{\text {th }}$ of the same month in Orestiada. The data analysis and de-recording was conducted after the ten interviews were completed and the oral speech was transferred to written records. The whole process lasted approximately 3 weeks. Additionally, the transcription process began after the first interview on 23 March 2017 and was completed on April 4, 2017.

\section{Sampling}

The participants of the research were 10 adult educators of both sexes who were occupied during the current academic year 2016-2017 in the two Lifelong Learning Centres. The sample was chosen randomly. Also, it can be referred as sample of convenience due to the short range of the research. The population was estimated homogenous by sharing a common characteristic: they were adult educators. Further endeavors were made to combine a variety of other characteristics such as the country of origin, the economic level, the teaching performance and the level of social behavior in order to increase the accuracy and reliability of the derived data.

\section{Data collection tool}

According to the protocols, each participant's interview was recorded to a portable recorder.

The tool was a questionnaire with a unique format, segmented in 5 separate classes including close and open questions in accordance to the topic while it was customised to reflect simplicity and preciseness. The interviewing process lasted from 15 to 25 minutes for each participant.

More specifically, the first question category included close questions in relation to demographic data referred in the interview format as Class A: Demographic 
information, requiring first name, age, marital status, studies, teaching experience, professional/occupational status, adult education is for you a: A) exclusive work or B) complementary work (select).

The second category included two open questions in order to introduce the participants normally to more complex questions or to make them feel comfortable with the interviewing process. This category was entitled as Class B: Professional career, asking the individuals to utter to the following: - Refer to your professional career to adult education?

-What were the reasons that prompted you to become involved in adult education?

The third category challenged the participants to answer by recalling their knowledge and by expressing their personal cogitations on critical questions such as to define who is an adult educator, to list his qualifications (typical and non typical), to comment on the training attendance, to criticise the necessity and the appropriateness of the training programmes and to refer to their occupation to the Lifelong Centres. More specifically, the third step was named

\section{Class C: Special Questions:}

- Who do you consider as an adult trainer? -What should be the appropriate training of an adult educator? - Have you attended a training program? (If so, how much and what, if not justify) -Do you think that the programs have responded to your needs? - If your answer was positive: evaluate their effectiveness. - Do you share the opinion that an adult trainer should attend training programs?

The fourth category monitored if the participants were familiar to the Greek established certification system EOPPEP, if they obtained a certificate and how important seemed EOPPEP to their career.

Consecutively, the interviewing questionnaire proceeded in Class D: Certification:

- Do you obtain adult educator's certification?

- Do you belong in any registry?

- Express your point of view regarding certification of educational competence. Do you consider it necessary? State your opinion.

In the last category, the participants were asked to provide information about the professional development of the examined field and if any chances to promote professional development existed. Moreover, they were asked to express their feelings on the adult educator as a separate profession. Finally, they were challenged to respond if training and certification promote professional development. This last question category was referred in the interviewing format as Class E: Professional development:

- Do you think that nowadays an adult educator is considered as a separate profession?

- Do you think adult education provides you opportunities to be professionally developed? Justify your answer.

- Do you think an adult trainer wishes to be developed in a professional level? Justify 
your answer.

- Do you think there are opportunities for professional development for an adult trainer? Make your references.

- In what way training contributes to the professional development of the field?

- Do you support the aspect that certification of qualifications is a form of professional development?

\section{Research main Findings}

Commenting on the findings it is clarified that they reassure the theoretical approach. As far as the first category is concerned, it should be mentioned that it is referred to close questions about demographic data collection. The results showed that the age of the participants ranged between 29 and 39 years old, while it was consisted of 5 men and 5 women. The participants to their total held an undergraduate degree related to their teaching subject. Simultaneously, 2 individuals completed post graduate studies on adult education. All of them had a significant experience on the field which ranged from 250 hours to 10 years. The principal results recorded that 10 out of 10 were occupied in the fields of adult education complementarily while all of them worked voluntarily without being paid obtaining at the same time their teaching experience certificate.

The second category included illustrative questions on the educators' professional progress and tried to explore the reason behind being occupied as adult educators. The derived data showed that the participants preferred adult education for a variety of reasons. 3 participants out of 10 expected a better professional future and as one of them stated "The reason I chose adult education was to gain teaching experience that would probably lead me to a better professional future"(Eleni). In addition, for 3 participants out of 10 adult education constituted a personal option, "I consider it as personal inclination and preference" (Sotiria). Furthermore, 3 out of 10 chose to work in the field because of the financial crisis and for gaining an extra income or in order to pass their leisure time creatively. Quoting on some of the participants' utterances: "I started two years ago, because of the economic crisis. My working hours have reduced and I had to cover up my free time creatively, even through volunteer work" (Andreas), "The reasons were highly economic" (Georgios).

The third category tried to specify more deeply and was associated with special questions on the terms of training and skills. The majority of them (8 people) participated in a training seminar but they still seemed to hesitate about the outcome and the benefits that had been provided to them. Attending various training programmes or seminars appeared to be effective but a significant part expressed disappointment concerning their appropriateness and adaptation to real teaching environments. Citing on some remarkable responses, the individuals were expressed as it follows: "I think the theory is far from the practice"(George), "The knowledge I received was very important to me"(Sotiria), "The training programs I attended fulfilled my expectations" (Mary), "I consider it a waste of time" (Konstantinos). The following table depicts the training tendency of the ten educators. 
The thoughts being expressed on the necessity of the training programs were in their total positive: "It is necessary for an adult trainer to be trained continuously because this is how he gets better in his role" (Mary), or "I believe he should be constantly informed about the new teaching methods" (Konstantinos) and finally, "It is a great opportunity to be informed, to learn, to revise, to apply and to experiment in practice what has been taught during the seminars" (Sotiria).

Proceeding to the third category, the participants owed not only to respond to the two main questions but also to give a definition of who is supposed to be an adult educator and what qualifications should someone possess. An adult educator was defined as the person who was occupied to the non formal education, someone who trained adults, someone who wished to be trained continuously or someone who had certified his qualifications. "I consider him as the one who has as his main job to train adults" (George), "An adult trainer is one who has the appropriate knowledge to teach adults" (Panagiotis), "Whosoever wishes to teach adults" (Katerina), "The one who has been certified and trained as an adult trainer" (Andreas), "An adult trainer is a professional who has the qualifications for pursuing a profession and is able to fulfill his educational goals" (Athanasia). The answer in the question about the educators' qualifications varied while at the same time brought together typical and non typical skills. An educator appeared as an informed individual having democratic beliefs, promoting dialogue and critical thinking. Additionally, he was derived to possessing great communicational skills and providing motivation to others. He seemed to be an expertise in his studies. Finally, he appeared equipped with patience managing to decentralize the role of the typical teacher. "I think he should be equipped with patience and perseverance, he should be continually informed and educated using new methods and technology as well as relying on dialogue" (Mary), "He should have the charisma of combining and adapting having a humble character. Trainee adults are very demanding"(Panagiotis), "Communication is everything "(Konstantinos).

Asking the ten educators if there were existed any parameters that they wished to evaluate, all of them agreed and expressed ten different aspects "Yes, I would like to improve the technology involvement in the course"(Christos)," I want to be exercised on the emotional intelligence" (Athanasia), "Personally, I would like to improve the part of managing people who create obstacles during the course "(Mary).

Shifting the question on the appropriate studies of an adult educator, 8 individuals uttered that it was essential to hold post graduate studies on adult education while 2 participants theorized that seminars and training were the key to success. "The trainer should definitely have a master's degree" (Panagiotis), "I think he should have higher education and postgraduate studies" (Athanasia),

The fourth category referred on the expressed thoughts on the Greek certification system. Only 3 out of 10 participants have certified their qualifications. The main reason that was laid behind the low participation in the examination was that in the province areas small rates of unemployment or antagonism were recorded. Simultaneously, both approving and disapproving points of view were expressed. Certification seemed not to be an important reason in occupation. Participants claimed that the wrong strategies, the bureaucracy, the time consuming process and the cost made the organisation problematic, dysfunctional and not innovative in relation to the knowledge that was offered. On the other hand, certification constituted the first step for 
objectivity in the field of adult education, separating people who really wished to be professional educators and it was claimed essential for someone who wanted to reassure his working position. "I consider the obtaining of the certificate important because through the process it will be clear who is really able to work as an adult educator"(Mary),

"I think that as long as there are occupational opportunities, it is not so necessary to obtain it because the working antagonism is not as great as in the big city centers" (Georgios), "I think it is necessary but it is time-consuming. Only those who own it should work in as educators"(Christos),"It is essential and very important to highlight who is an adult trainer. However, the examination seems a bit incomplete and dysfunctional"(Andreas), "I consider certification a remarkable step for objective assessment on the qualifications of adult educators, but when I participated in the examination I noticed many shortcomings referring to the coordination and organization of EOPPEP. I considered the process of examining micro-teaching unfair"(Eleni). Asking the part of the participants who did not wish to obtain a certificate on their skills they responded that there was no further knowledge offered to acquire while the participation fee was estimated high.

The fifth and last category was consisted of questions about the professional development of the field. The majority cogitated that adult education was not a complete or defined profession due to the instability and the complementary character of the occupation. One participant believed that this occurred because there were core differences between adult education and typical educational system. They noticed that there was a tendency for professional development not only by the side of the educators but also from the one of the Greek state. Besides, the chances for the educators were not numerous and they were not being paid properly. The general aspect depicted a strong preference in adult education because of the financial crisis and due to the fact that Greek adult education presented potential progress. All respondents replied that they did not believe that under the existing conditions they could be considered as professionals, but as complementary or occasional teachers, since they did not feel stability and security. "I think there is a great difference. Personally, I believe this happens because it differs from teaching children "(Mary) "For me an adult educator is not a profession because no one can teach continuously but only occasionally" (Georgios). In addition, they expressed the opinion that even though an adult trainer attempted to create a profession there was no special opportunities for professional development. "I think adult education is growing rapidly during recent years and the adult trainer has several but not many opportunities for professional development. There are very good bases for someone who wants to be developed but I am negative because the chance to work is only for a limited time period"(Mary), "I think professional development exists because of the crisis, most people work in the adult education field because they do not have other opportunities like me. There may be opportunities for professional development because of the huge number of the training organizations but I think it has an expiring date"(Panagiotis) "There are opportunities for someone who wants to seize them. The Educators' Registrer and the EOPPEP exams are considered to be the first step towards professional development "(Athanasia),"I do not think there are any remarkable prospects" (Sotiria), I believe that despite personal study, strong effort and continuous training, the state seems to 
ignore the professional development of the sector" (Eleni). Asking the participants if training contributed to the professional development of the adult educator, the views expressed by the participants were mostly positive, but some negative opinions were also heard." It is a personal preference how much and on what each one will be trained" (Eleni) "Without training there is no growth" (Katerina) finally, on questioning whether qualification certification was a form of professional development, the opinions that were stated were diametrically opposed. Participants did not believe that the aforementioned certification was something that would contribute to the professional organization while others consider EOPPEP a prerequisite. "I do not think that certification is yet another skill to prevent the trainer from losing his job" (Mary), "It could be considered a form of professional development because candidates will go through issues that deal with adult education" (Georgios).

\section{Discussion and Conclusion}

This study was conducted in order to identify the personal views of the 10 adult educators and how they were incorporated to the professional development model. It was estimated that the educators did not possess the typical or the appropriate skills while the minority certified their qualifications. The certification concept was characterized ambiguous. A strong aspect that was derived was that the acquired knowledge should be officially recognized as in the case of EOPPEP, the Greek qualification certification organisation, but the educators did not feel the need to certify their skills due to the low competing rate. In addition, those who experienced the examination process insisted that it was rather problematic, feeling at the same time reluctant about the offered benefits. Certifying the existing qualifications proved controversial in this research. According to the General Secretariat of Lifelong Learning and Youth "the educational competence is defined as the proven response to professional examination by confirming existing knowledge, skills and experience as they are applied on the Certified Professional Outline of Adult Trainers in correspondence to the framework of educational Trainers" programmes (General Secretariat of Lifelong Learning [GSLL], 2013). Although the overwhelming majority regarded educational competence as a necessary skill, they did not obtain it and did not belong to the Adult Trainer Sub-Register. Those remarkable conclusions confirmed the necessity to provide quality and objectivity in Adult Education (Sotiropoulou, 2008). It was admitted that the participation in training seminars and the presence of certification offered by EOPPEP updated the trainer to seize the opportunity to be developed (Tsopozidou, 2014). EOPPEP is the first established and organized effort of the Greek state being in a developmental stage (Savvaki, 2016). Moreover, obtaining educational competence prioritized an adult trainer. EOPPEP proved to be the only organization in our country that promoted professional development, gave prestige and clarified the different concept of adult education. Certification was estimated to lead to socio-economic development, making necessary to alter the underestimated view on adult education due to the existence of unilateral actions. 
The positive aspects about training were encouraging while the sample appeared rather skeptical on the issue if those seminars addressed their more and more increasing needs realizing at the same time the difficulties that would be faced when applied in the class. There was a great disappointment because of the occupational instability and the economical issues due to the financial crisis occurring in Greece the last 8 years. Those who attended a relevant programme admitted that their participation had greatly improved their effectiveness by making them better adult educators with experience on teaching techniques and methods while others identified obstacles that they encountered during the learning process. Citing on Mavrogiorgos's view (2009), training on non-formal education contributed positively and responded to needs by providing to the trainers the opportunity to renew and to improve their educational and professional level. Then, it became feasible for the educator, to be updated and more effective and competitive. According to Giannakopoulos (2015), the factors that contributed to the effectiveness of the training was the target of realistic goals, the link of the theoretical knowledge with the practical application, the possibility of collaborative learning as well as the flexibility of the forms of learning according to the needs.

Potential dissatisfaction during participation in training programmes is confirmed by Giannakopoulos (2015) stating that "the results of the training have not been sufficiently explored in terms of the features that make it effective. The given impression supported that education was spasmodic and uncoordinated which is reasonable because 'in Greece there is a lack of organized and effective strategies' (Giannakopoulos, 2015, p. 34).

Generally speaking, it was admitted that the adult educator's dimensions differ radically from the theory to the real practice. The qualifications of an Adult Trainer were not restricted on the high educational level but they appeared as a constant combination of the characteristics of an individual, the gained experience and the practical applications of the teaching techniques. The respondents uttered that those adult educators should have theoretical knowledge of the subject they teach, transmissibility, adaptability, emotional intelligence and animosity. On top of that, it proved important not only to be insistent but also to be familiar with technology and informed about innovative learning techniques. The list of qualifications of a competent Adult Teacher is long and combines characteristics from different fields of science such as pedagogy, sociology and psychology, but according to Pazianou (2007) in many teaching schools training on sociology and psychology was degraded to nonexistent. Tsakirides (2016) claimed that the qualifications of an adult trainer were typically and materially categorized. Regarding qualifications, an adult educator seems to be a complex character devoted to his job and focused on the humanized kind of education (Tsakirides, 2016).

Another point that should be mentioned was the dominant notion of the professional development. In Greek reality the chances for an educator exist but they are extremely limited. People who wanted to fulfill the role of the professional teacher were often marginalized without even forming a separate 
scientific field. In addition, as far as the professional development of the field is concerned, respondents believed that it ceased to grow and a respected part of trainers considered the future to be ominous due to the current financial crisis. As Tsopozidou (2014) argued, there was a fictitious line of the preconditions of the professional development on adult educators. According to several academics, professional development seemed to be linked and influenced not only by the personal and professional choice but also by the trainer's identity shaping. These components remained fluid when examining the changing social economic context, the expectations and the trainers' needs.

Additionally, the population admitted that many things should be changed, developed and revised. Not surprisingly, the educators were familiar with the fact that adult education was yet an emerging and a very promising field for someone who wanted to be a professional.

This study is suggested to those who are willing to investigate thoroughly the reasons and the obstacles of the adult educators' professional development expressing their wish to criticize on the established systems of certifying the qualifications. The present approach clarifies the problems that are encountered in Lifelong Learning Centers while it simultaneously enriches the existent literature offering ideas for further research. A further examination of the issue, based on the derived data of the present research, is recommended. The sample should be expanded including participants from a wider variety of centers and scientific fields from all over the country. Furthermore, the Greek government and the responsible ministries should be informed about the problems that are demonstrated during the current research in an attempt to make them aware of them and lead to their solution. Therefore, it is thought that the present research could constitute the tinder for the development and the elimination of obstacles in the fields of Lifelong Learning in Greece.

Furthermore, the under research topics could be conducted in a quantitative research by distributing questionnaires to adult educators and educational managers or programme advisors from all the Greek Lifelong Learning Centers. This could lead to the examination of various hidden fields concerning Lifelong Learning.

\section{Acknowledgements}

The authors would like to thank Mr. Efthymios Valkanos, Associate Professor of the University of Macedonia and Mr. Iosif Fragkoulis, Professor of Hellenic Open University for supervising and supporting the present study.

\section{References}

Blackman, A. (1989). Issues in professional development: the continuing agenda. In Mary Louise Holly \& CavenS. Mcloughlin (eds.), Perspectives on Teacher Professional Development. London: The Falmer Press.

Cedefop, (2009) : Winterton, J., Delamare, F., \& Stringfellow, E. . Typology of knowledge, skills and competences: clarification of the concept and prototype. Retrieved from http://www.cedefop.europa.eu/en/publications-and resources/publications/3048. 
Giannakopoulos, A. (2015). Teachers' views on the contribution of non-formal education to their professional development (Master's Thesis). HOU, Patras, p. 34.

Greenhaus, J. (1987). Career Management. Chicago: Dryden Press.

National Organization for the Certification of Qualifications and Vocational Guidance. (2012). Retrieved from http://www.eoppep.gr/index.php/el/eoppep/framework/category/10-legalframework-eoppep.

Jarvis, P. (2004). Adult Education and Lifelong Learning: Theory and Practice (3rd ed.). London: Falmer Press. Retrieved from http:// site.ebrary.com/lib/oculryerson/docDetail.action?docID=10093530\&p00 Doi: https:// doi.org/10.4324/9780203561560.

Jogi., L.\& Gross., M. (2009) The Professionalization of Adult Educators in the Balti States, European Journal of Education, 44(2), 221-242. doi: https://doi.org/10.1111/j.1465-3435.2009.01380.x.

Kedraka, Aik. (2009). Adult Educators in Greece: Development, researches, wonderings. Thessaloniki: Br.Kyriakides.

Levinson, S. C. (2002). Time for a linguistic anthropology of time. Current Anthropology. Retrieved from http://www.journals.uchicago.edu/doi/10.1086/342214. Doi: http://dx.doi.org/10.1525/jlin.1999.9.1-2.144.

Lester, P. (2000). Visual Communication Images and Messages. Belmont: Wadsworth Publishing Company.

Lifelong Learning Centres, (2014). Retrieved from http://www.kdvm.gr/about

Lifelong Learning Secretariat (2013). Retrieved from http://www.gsae.edu.gr/el/glossari?id=690.

Mavrogiorgos, G. (2011). Teacher education: Why teachers do not be treated as adult intellectuals. Athens: Pedio.

Mocker D. \& Noble, E. (1981). Training part-time instructional stuff, in S. Grabowski (ed.) Preparing Educators of Adults. San Francisco: Jossey- Bass, pp. 45-61.

Pizanou, E. (2007). The contribution of training to the professional development of secondary education teachers. The case ofthe Lesbos Island (Master's Thesis). HOU, Patras.

Rogers, A. (1999). Adult Education. Athens: Metaichmio.

Savvaki, Ch. (2016). Perceptions of trainers of adult educators' trainers and learners on the modern role of adult educators (Master's Thesis). HOU, Patras.

Sotiropoulou, A. (2008). Incentives for the participation of adult trainers in informal learning (Master's Thesis). HOU, Patras.

Tsakirides, A. (2016). Investigating the views of adult teachers of non-formal education on their role (Master's Thesis). HOU, Patras.

Tsigarida, E. (2014). The Professional Identity and Self-Advocacy of Adult Trainers in Greece (Master's Thesis). HOU, Patras.

Tsopozidou, L. (2014). The professional profile of adult trainers in Greece: Issues on developing skills in the workplace (Master's Thesis AUTh. Thessaloniki, Greece). Retrieved from: https://ikee.lib.auth.gr/record/267627/files/GRI-2015-14476.pdf. 